\title{
EXPRESSION OF VASCULAR ENDOTHELIAL GROWTH FACTOR DURING HEALING OF EXTRACTION SOCKETS IN DIABETIC RATS

\author{
El Hady $\mathrm{T}^{1}{ }_{B D S}$, Karam $\mathrm{S}^{2} P h D$, El Sawa $\mathrm{A}^{2} P h D$, Saad $\mathrm{N}^{3} P h D$
}

\begin{abstract}
:
Introduction: Vascular endothelial growth factor (VEGF) is one such candidate. It functions as an endothelial cell mitogen, chemotactic agent, and inducer of vascular permeability. Other angiogenic growth factors such as basic fibroblast growth factor (bFGF) and transforming growth factor $\beta$ (TGF- $\beta$ ) have been described, but VEGF is unique for its effects on multiple components of the wound healing cascade, including angiogenesis and recently shown epithelization and collagen deposition. VEGF is produced by many cell types that participate in wound healing: endothelial cells, fibroblasts, smooth muscle cells, platelets, neutrophils, and macrophages.

Objectives: To evaluate the expression of VEGF during healing of extracted sockets in diabetic rats.

Materials and methods: 24 adult male rats aged about 6 months and weighing about 250 gms were divided into 2 groups; Group I (12 rats) non diabetic and Group II (12 rats) diabetic. For study group, the rats were fasted overnight and diabetes was induced by a single intra peritoneal injection of streptozotocin $60 \mathrm{mg} / \mathrm{kg}$ body weight in $0.1 \mathrm{M}$ citrate buffer. All animals, were exposed to surgical wounds (extracted lower right first molar). They were sacrificed as follows 4 rats from each group at intervals of 3 days, 7 days, 21 days after extraction for immunohistochemical study.

Results: In the present study, immunohistochemical expression of VEGF was detected as brown cytoplasmic reaction. All the examined cases showed positive results for VEGF with different scores.

Conclusions: these results demonstrated the expression of VEGF in diabetic rats during healing of extraction sockets significantly higher than control group in late periods.

Key words: VEGF, Extraction wound healing, diabetes, immunohistochemistry.

1- Master student at the Oral Biology Department, Faculty of Dentistry, Alexandria University, Alexandria, Egypt.

2- Professor of Oral Biology, Faculty of Dentistry, Alexandria University, Alexandria, Egypt.

3- Lecturer of Oral Biology, Faculty of Dentistry, Alexandria University, Alexandria, Egypt.
\end{abstract}

\section{INTRODUCTION}

Wound healing is a sequence of cellular and biological response directed toward restoring tissue integrity and functional capacity following injury (1).

The inflammatory stage occurs during the first week of healing. White blood cells enter the socket to remove contaminating bacteria from the area and begin to break down any debris, such as bone fragments, that are left in the socket (2).

In the second week the healing continues to get organized through fibroplasia and new blood vessels that begin to penetrate towards the center of the clot. Trabeculae of osteoid slowly extend into the clot from the alveolus, and osteoclastic resorption of cortical margin of the alveolar socket is more distinct (1). In smaller sockets the epithelium may have become fully intact by this point (2).

By the third week the extraction socket is filled with granulation tissue and poorly calcified bone forms at the wound perimeter (1).

Diabetes mellitus is a group of metabolic diseases in which a person has high blood glucose either because the body does not produce enough insulin, or because cells do not respond to the insulin that is produced by the pancreas. This resulting high blood sugar produces the classical symptoms of polyuria: frequent urination polydipsia (increased thirst) and polyphagia (increases hunger) (3).

Modelling and establishment of new blood vessels is critical in wound healing and takes place concurrently during all phases of the reparative process. In addition to attracting neutrophils and macrophages, numerous angiogenic factors secreted during the haemostatic phase promote angiogenesis (4).

Resident endothelial cells are responsive to a number of angiogenic factors, including FGF, VEGF, PDGF, angiogenin, TGF- $\beta$ and TGF- $\alpha$. A fine balance is kept by the action of inhibitory factors, such as angiostatin and steroids (5). Inhibitory and stimulatory agents act on proliferating endothelial cells directly as well as indirectly, by activating mitosis, promoting locomotion and by stimulating the host cells to release endothelial growth factors (6).

Under hypoxic conditions, molecules are secreted from the surrounding tissue, promoting proliferation and growth of endothelial cells. In response, a four-step process takes place: (i) production of proteases by endothelial cells for degradation of the basal lamina in the parent vessel in order to crawl through the extracellular matrix, (ii) chemotaxis, (iii) proliferation, and (iv) remodeling and differentiation. FGF and VEGF play central regulatory roles in all of the processes (7).

Initially, there is no vascular supply in the wound centre, so viable tissue, which is limited to wound margins, is perfused by uninjured vessels and by diffusion through undamaged interstitium (8). Capillary sprouts from the surrounding edges invade the wound clot and, within a few days, a microvascular network composed of many new capillaries is formed (9).

Chemotaxis is the ability of cells to move along a chemical gradient (10). This biochemical mechanism enables cells to reply properly to environmental stimuli that determine proliferation, differentiation and migration. 
Chemotactic agents act on cell surface receptors to direct the cell migration that is involved in angiogenesis during wound healing (11).

Migration is the consequence of chemotacitc activity and is necessary for angiogenesis (12).

Vascular endothelial growth factor (VEGF) is one such candidate. It functions as an endothelial cell mitogen, chemotactic agent (13), and inducer of vascular permeability (14). Other angiogenic growth factors such as basic fibroblast growth factor (bFGF) and transforming growth factor $\beta$ (TGF- $\beta$ ) have been described, but VEGF is unique for its effects on multiple components of the wound healing cascade, including angiogenesis and recently shown epithelization and collagen deposition (15).

\section{MATERIALS AND METHODS}

A clinical trial was conducted on ten adult patients of both Experimental animals: All experimental animal procedures were approved by faculty institutional ethics committee. Twenty four adult male rats weighing about 200-250 gms, and aged about 6 months were used in this study. These animals were obtained from the Institute of Medical Research Alexandria University. Animals were housed in specially designed wire mesh bottom cages, three animals per cage. All the animals were supplied a regular and the same diet adlibitum throughout the whole experimental period. The study included the following groups:

Group I: (12 rats).

Group II: (12 rats) with induced diabetes.

\section{Methods}

\section{Preoperative phase}

Induction of diabetes:

For study group, the rats were fasted overnight and diabetes was induced by a single intraperitoneal injection of streptozotocin $60 \mathrm{mg} / \mathrm{kg}$ body weight in $0.1 \mathrm{M}$ citrate buffer (16).

Streptozotocin (STZ) was freshly prepared immediately before injection, and it was kept in cold store and refrigerator temperature $\left(2-8^{\circ} \mathrm{C}\right)$ away from light. If it is not used fresh, streptozotocin solution can exhibit reduced ability to induce diabetes (17).

At the time the animals were entered the study, their body weight and blood glucose level were recorded then they were measured 48 hours after the administration of streptozotocin, then every two weeks throughout the time of the experiment.

\section{Operative phase \\ Anaesthesia}

Each animal received general anaesthetic solutions of $10 \%$ $(40 \mathrm{ml} / \mathrm{k} \cdot \mathrm{gm}$ body weight) and zylazine $2 \%(5 \mathrm{mg} / \mathrm{k} . \mathrm{gm}$ body weight)

\section{Surgical procedures}

The surgical site was disinfected using iodine swab, extraction of mandibular right 1 st molar of all animals was carried out.

Animals euthanasia:

Four animals in each group were sacrificed at 3, 7, and 21 days following tooth extraction. Jaws were dissected, and specimens were fixed in $10 \%$ formalin saline for 7 days to be prepared for Immunohistochemical study.

\section{Immunohistochemical evaluation:}

Immunostaining for VEGF using anti-rabbite polycolonal antibody, clone Po-A (ready to use) was done according to kit manual. Antigen retrieval using citrate buffer, (PH 0.6) was done for 1 hour at $40{ }^{\circ} \mathrm{C}(18)$.

\section{Assessment of VEGF expression}

The presence of brown cytoplasmic precipitate in the inflammatory cells and others indicated positive reaction. Tissue sections were examined under light microscopy at x100 magnification in order to identify five fields with the largest number of immunostained cells using $x 400$ magnification, the counting of the immunopositive cells was performed in each one of these fields.

Immunoexpression of VEGF was classified according to Ruiz et al (19) to the following scores: 0 - no staining; 1 - weak, staining in $11-25 \%$ of cells; score 2 - moderate, staining in $26-75 \%$ of cells; score 3 - strong, staining in more than $76 \%$ of cells.

\section{RESULTS}

In the present study, immunohistochemical expression of VEGF was detected as brown cytoplasmic reaction. All the examined cases showed positive results for VEGF but in different scores.

\section{3 days after tooth extraction}

In all studied cases, the VEGF immune staining was detected in inflammatory cells, endothelial cells, fibroblast, osteoblast cells.

In group I, score for the VEGF expression ranged from 2 - 3 Fig. 1(A), in the median (2.0-3.0) (Table 1).

In group II, score for the VEGF expression ranged from $2-3$ Fig. 2 (A), in the median (2.0-3.0) (Table 1).

\section{7 days after tooth extraction:}

In all studied cases, the VEGF immune staining was detected in endothelial cells, fibroblast, osteoblast cells and residual inflammatory cells.

In group I, score for the VEGF expression ranged from 2 - 3 Fig.1 (B), in the median (2.0-3.0) (Table 1).

In group II, score for the VEGF expression ranged from 2 - 3 Fig. 2 (B), in the median (2.0-3.0) (Table 1).

\section{1 days after tooth extraction}

In all studied cases, the VEGF immune staining was detected in inflammatory cells, endothelial cells, fibroblast, osteoblast cells.

In group I, score for the VEGF expression ranged from $1-2$ Fig. 1 (C), in the median (1.0-2.0) (Table 1).

In group II, score for the VEGF expression ranged from $2-3$ Figs. 2(C), in the median (2.0-3.0) (Table 1).

Using Mann Whitney test to compare between the different periods Wilcoxon signed ranks test was applied, in group I, no significant changes between 3 days and 7 days p1 (1.000), whereas statistically significant changes were 
observed between 3 days and 21 days p2 (0.038) and statistically significant change between 7 days and 21 days p3 (0.059).

In group II, no significant changes between 3 days and 7 days p1 (1.000), and no significant changes between 3 days and 21 days $\mathrm{p} 2(0.083)$ and no significant changes between 7 days and 21 days $\mathrm{p} 3(0.083)$.

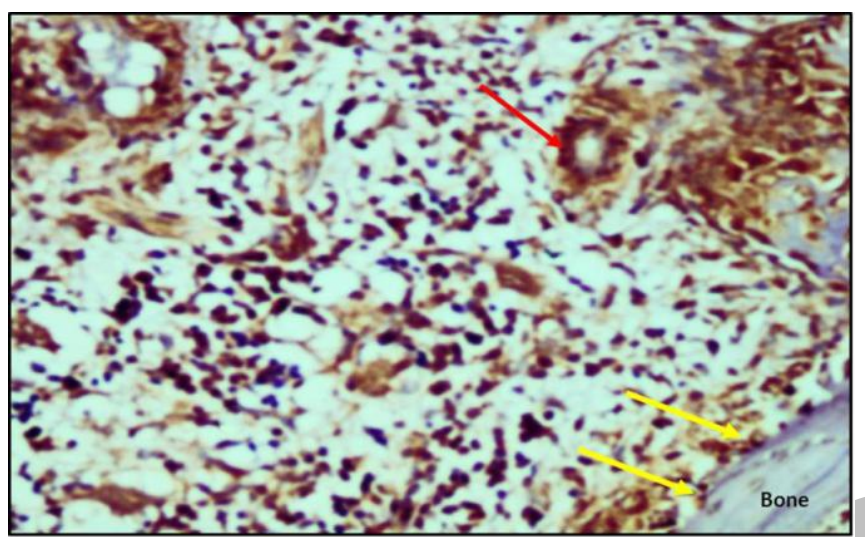

Fig. 1 (A): Group I after 3 days showing moderate cytoplasmic brown colouration in $\geq 26 \leq 75 \%$ of inflammatory cells, endothelial cells (red arrow) and osteoblast (yellow arrow) (VEGF, Avidin biotin, DAB x 400).

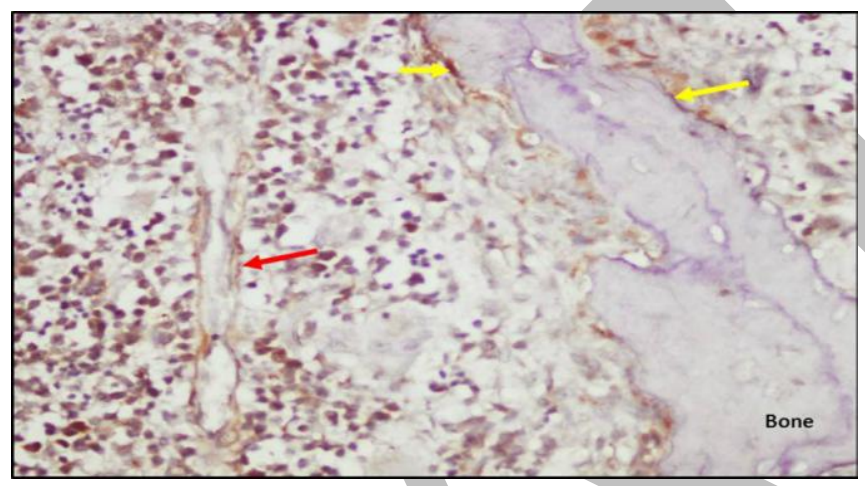

Fig. 2 (A): Group IV after 3 days showing strong cytoplasmic brown colouration in $\geq 76 \%$ of inflammatory cells, osteoblast cells (yellow arrow) and endothelial cells (red arrow) (VEGF, Avidin biotin, DAB x 400).

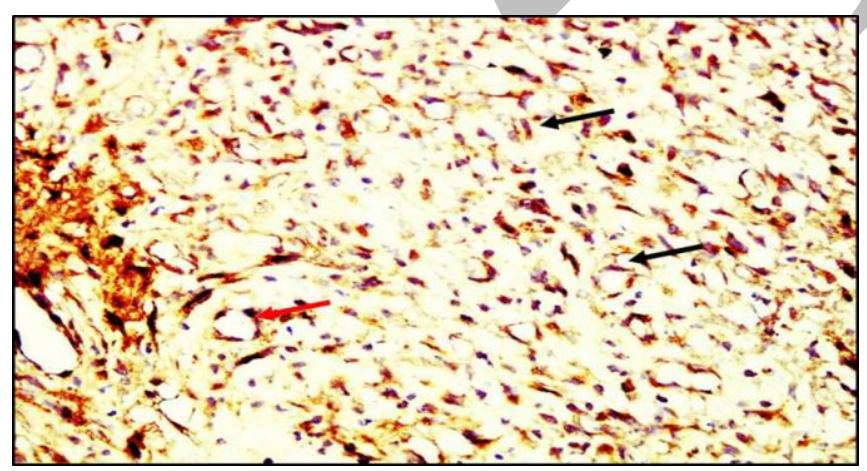

Fig. 1 (B): Group I after 7 days showing strong cytoplasmic brown colourationin $\geq 76 \%$ of endothelial cells (red arrow), fibroblast (black arrow), and residual inflammatory cells (VEGF, Avidin biotin, DAB x 400)

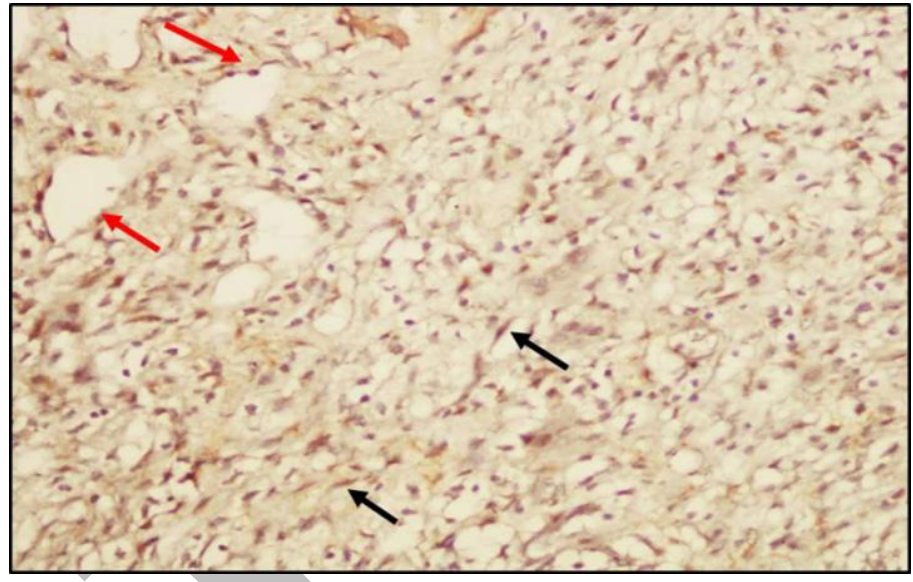

Fig. 2 (B): Group III after 7 days showing strong cytoplasmic brown colouration in $\geq 76 \%$ of inflammatory cells, endothelial cells (red arrow) and fibroblast cells (black arrow) (VEGF, Avidin biotin, DAB x 400)

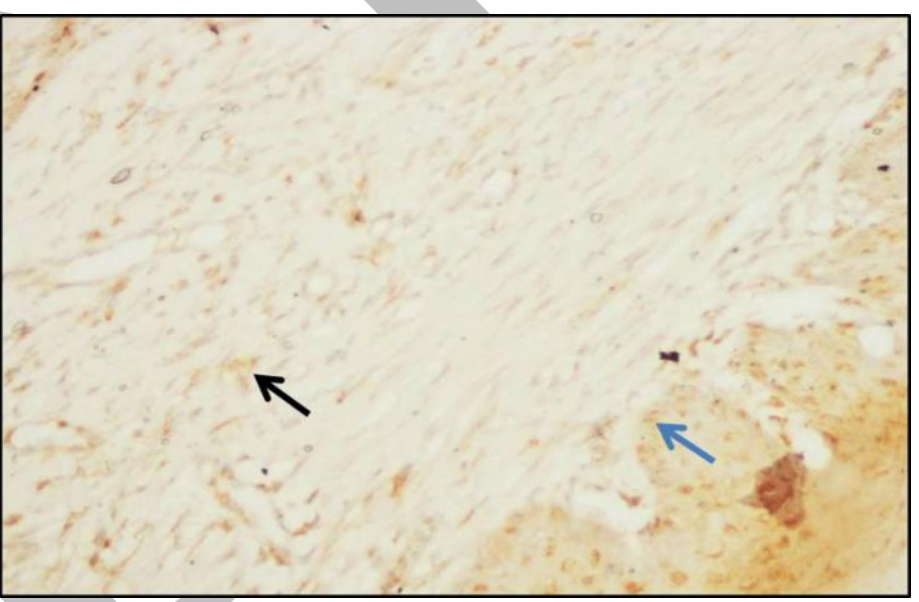

Fig. 1 (C): Group I after 21 days showing weak cytoplasmic brown colouration in $\geq 11 \leq 25 \%$ of keratinocytes (blue arrow) and fibroblast cells(black arrow) (VEGF, Avidin biotin, DAB x 400).

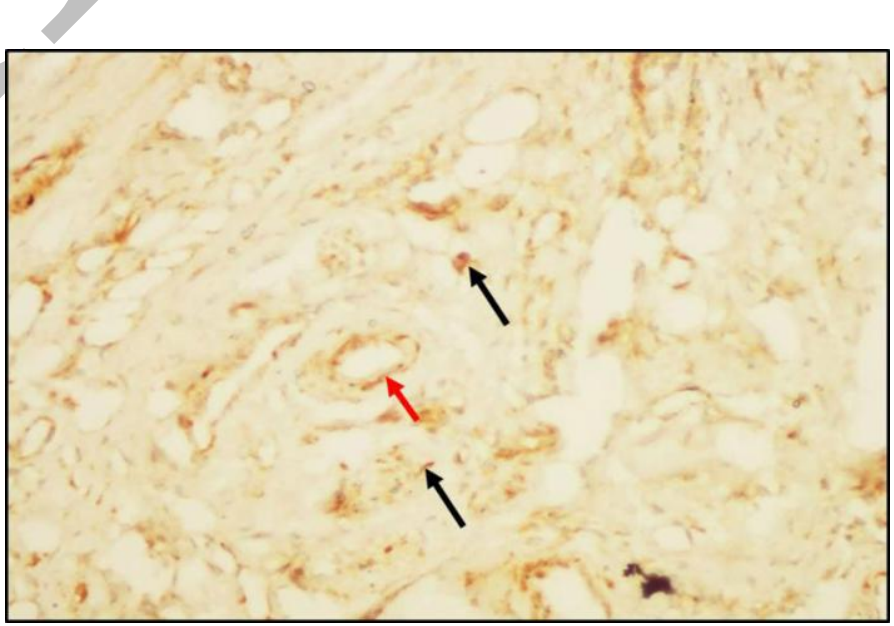

Fig. 2 (C): Group III after 21 days showing moderate cytoplasmic brown colouration in $\geq 26 \leq 75 \%$ of endothelial cells (red arrow) and fibroblast cells(black arrow) (VEGF, Avidin biotin, DAB $\mathrm{x}$ 400). 
Table (1): Comparison between the two studied groups according to expression of VEGF during the healing of extracted socket in diabetic rats.

\begin{tabular}{||cccc|}
\hline & \multicolumn{3}{c|}{ After extraction } \\
& 3 days & $\mathbf{7}$ days & 21 days \\
\hline Group I & $3.0(2.0-3.0)$ & $3.0(2.0-3.0)$ & $1.0(1.0-2.0)$ \\
Sig. bet. periods & \multicolumn{3}{c}{$\mathrm{p}_{1}=1.000, \mathrm{p}_{2}=0.038^{*}, \mathrm{p}_{3}=0.059$} \\
Group II & $3.0(2.0-3.0)$ & $3.0(2.0-3.0)$ & $2.0(2.0-3.0)$ \\
Sig. bet. periods & \multicolumn{3}{c}{$\mathrm{p}_{1}=1.000, \mathrm{p}_{2}=0.083, \mathrm{p}_{3}=0.083$} \\
p & 1.000 & 1.000 & $0.042^{*}$ \\
\hline \hline
\end{tabular}

Abnormally distributed data was expressed in median (Max.- Min.) and was compared using Mann Whitney test. To compare between the different periods Wilcoxon signed ranks test was applied

p1: $p$ value for comparing between 3 days and 7 days p2: $\mathrm{p}$ value for comparing between 3 days and 21 days p3: $p$ value for comparing between 7 days and 21 days *: Statistically significant at $\mathrm{p} \leq 0.05$

\section{DISCUSSION}

The VEGFs and their corresponding receptors are key regulators in a cascade of molecular and cellular events that ultimately lead to the development of the vascular system, either by vasculogenesis, angiogenesis or in the formation of the lymphatic vascular system (20).

Although VEGFs' main effects are on endothelial cells, they also bind to VEGF receptors expressed on monocytes, neurons, chondrocytes and osteoblasts (21).

Recent studies have shown that the combination of angiogenic and osteogenic factors can stimulate bone healing and regeneration (22).

Both osteogenesis and angiogenesis are integrated parts of bone growth and regeneration. Combined delivery of osteogenic and angiogenic factors is a novel approach in bone regenerative engineering. Exogenous addition of vascular endothelial growth factor (VEGF) and bone morphogenetic proteins (BMPs) together with an osteoconductive scaffold is a very promising method to enhance bone repair (23). Therefore the present study was designed to evaluate the expression of VEGF in healing of extraction socket in diabetic rats.

The present result revealed positive expression of VEGF by inflammatory cells, precursor endothelial cells, keratinocytes, and bone cells including osteoblasts and active osteocytes in different periods in all groups but in different scores. These results are in agreement with E. Fadhil et al (24), who found positive expression of VEGF by bone marrow stromal cells, adipocytes, mesenchymal stem cells, precursor endothelial cells, and bone cells including osteoblasts and active osteocytes in different periods in all groups but in different score Therefore, his data provide evidence that VEGF activity is essential for appropriate bone formation and mineralization in response to injury.

VEGF is produced by many cell types that participate in wound healing: endothelial cells (25), fibroblast (26), smooth muscle cells (27), platelets (28) and neutrophils (29).

In the present study, figure $1(\mathrm{~A}, \mathrm{~B}) \&$ figure $2(\mathrm{~A}, \mathrm{~B})$ show positive cytoplasm immuno staining in endothelial cell of newly formed capillaries. One of VEGF's roles in wound healing is in stimulation of angiogenesis. Wound healing angiogenesis involves multiple steps including vasodilation, basement membrane degradation, endothelial cell migration, and endothelial cell proliferation (30).

VEGF induces endothelial cell migration in wound healing through two primary mechanisms, chemotaxis and vasodilatation. In the initial phase of angiogenesis, endothelial cells migrate before mitotic division (31).

Mechanism I: Chemotaxis-Chemotaxis is a highly regulated process involving cell adhesion molecules' interaction with the extracellular matrix (32).

Mechanism II: Increasing vascular permeabilityAnother mechanism by which VEGF induces endothelial cell migration in wound healing is related to the increase in vascular permeability mediated by $\mathrm{NO}$ and prostacyclin. Leakage of the plasma protein fibrinogen and its subsequent conversion in the extracellular space to a fibrin gel stimulates endothelial migration (33).

In the present study, figure 1 (C) shows granulation tissue formation established healing responses. An essential feature of normal wound repair is the formation of granulation tissue, i.e. fibrovascular tissue containing fibroblasts, collagen and blood vessels, which is the hallmark of an established healing response (34).

In addition, VEGF does not only contribute to vasculogenesis in the embryonic period and angiogenesis of normal tissues such as smooth muscle, cardiac muscle, and liver but is also secreted at solid cancer and inflammatory tissues and is closely involved in pathological angiogenesis in the many diseases including cancer, chronic rheumatoid arthritis and diabetic retinopathy (35).

Presently, VEGF is used clinically as a blood test item. The circulating VEGF concentration has been reported to be significantly higher in patients with various diseases in which VEGF is associated with pathological angiogenesis than in healthy Individual (36).

Kakizawa et al (37), compared the serum VEGF concentration between diabetic patients and healthy controls and reported that it was significantly higher in diabetic patients.

In the different groups the expression of VEGF was not significantly different at 3 and 7 days, but it was significantly different at 21 days.

In diabetic retinopathy, retinal vessels are damaged by abnormal metabolism due to hyperglycemia, hypoxia is induced by the occlusion of retinal vessels, and VEGF expressed at the site of vascular damage. Thus, it has been established that VEGF promotes pathological retinal angiogenesis (38). Moreover Takayama et al reported that the serum VEGF concentration was significantly higher in patients with diabetic retinopathy than without, they suggested that VEGF expressed in the retina affects the serum VEGF concentration through peripheral blood vessels (39). Also, it has been reported that diabetic rats show marked VEGF expression at the site of surgery and associated pathological angiogenesis and vascular hyper permeability which affect the delay in wound healing after 
periodontal surgery compared with normal rats confirming our results of delayed healing in group III.

\section{CONCLUSIONS}

From the results of the current study, the following can be concluded:

- Expression of VEGF in diabetic rats during healing of extraction socket is higher than control group in late period.

Diabetes is considered an important risk factor for severe infection of the wound.

Diabetes induction impaired healing of extraction wound in comparison with non diabetes group.

\section{ACKNOWLEDGEMENT}

The authors would like to express thanks to the department of Oral Biology at the Faculty of Dentistry, Alexandria University and to their families for their support throughout the study.

\section{CONFLICT OF INTEREST}

The authors declare that they have no conflicts of interest.

\section{REFERENCES}

1. Miloro M, Ghali GE. Peterson's principles of oral and maxillofacial surgery, 2nd ed. London: BC Decker; 2004. 3-14.

2. Peterson LJ, Ellis E, Hupp J. Contemporary oral and maxillofacial surgery, 5th ed. St. Louis: Mosby Elsevier; 2008. 47-58.

3. McCance DR, Hanson RL, Peititt DJ, Bern-en PH, Hadden DR, Knowler WC. Diagnosing diabetes mslktiis-do we need new criteria. Diabetologia. 1997;4:247-55.

4. Servold SA. Growth Factor impact on wound healing. Clin Podiatr Med Surg. 1991;8:937-53.

5. Ribatti D, Vacca A, Roncali L, Dammacco F. Angiogenesis under normal and pathological conditions. Haematologica. 1991;76:311-20.

6. Ferrara N. Vascular endothelial growth factor and the regulation of angiogenesis. Recent Prog Horm Res. 2000;55:15-35.

7. English D, Kovala AT, Welch Z, Harvey KA, Siddiqui RA, Brindley DN, et al. Induction of endothelial cell chemotaxis by sphinosine 1- phosphate and stabilization of endothelial monolayer barrier function by lysophosphatidic acid, potential mediators of hematopoietic angiogenesis. J Hematother Stem Cell Res. 1999;8:627-34.

8. Robson MC, Steed DL, Franz MG. Wound healing: biologic features and approaches to maximize healing trajectories. CurrProbl Surg. 2001;38:72-140.

9. Velnar T, Bailey T, Smrkolj V. The wound healing process: an overview of the cellular and molecular mechanisms. J Int Med RCs. 2009;37:1528-42.

10. Manes S, Mira E, Gomez-Mouton C, Lacalle RA, Martinez C. Cells on the move: a dialogue between polarization and motility. IUBMB Life. 2000;49:89-96.

11. Hsu S, Thakar R, Li S. Haptotaxis of endothelial cell migration under flow Methods. Mol Med. 2007;139:237-50.
12. Li S, Huang NF, Hsu S. Mechanotransduction in endothelial cell migration. $\mathrm{J}$ Cell Biochem. 2005;96:1110-26.

13. Yoshida A, Anand-Apte B, Zetter BR. Differential endothelial migration and proliferation to basic fibroblast growth factor and vascular endothelial growth factor. Growth Factors. 1996;13:57-64.

14. Yamagishi S, Yonekura H, Yamamoto Y, Fujimori H, Sakurai S, Tanaka N, et al. Vascular endothelial growth factor acts as a pericyte mitogen under hypoxic conditions. Lab Invest. 1999;79:501-9.

15. Stojadinovic OKA, Golinko M, Tomic-Canic M, Brem H. A novel, non-angiogenic mechanism of VEGF: stimulation of keratinocyte and fibroblast migration. Wound Repair and Regeneration. 2007: A30.

16. Vincent AM, Russell JW, Low P, Feldman EL. Oxidative stress in the pathogenesis of diabetic neuropathy. Endocr Rev. 2004;25:612-28.

17. Martinez G, Al-Dalian SM, Menedez S, Guilian A, Leon OS. Ozone treatment reduces blood oxidative stress and pancrease damage in a streptozotocin induced diabetes model in rats. Acta Farm Bonaerense. 2005;24:49-7.

18. Shi SR, Key ME, Kalra KL. Antigen retrieval in formalin-fixed paraffin-embedded tissue, an enhancement method for immunohistochemical staining based on microwave oven heating of tissue section. J Histochem Cytochem. 1991;39:741-8.

19. Ruiz PA, DE Toledo OA, Nonaka CFW, Pinto LP, DE Souza LB. Oral Sci. 2010;18:12-9.

20. Tammela T, Enholm B, Alitalo K, Paavonen K. The biology of vascular endothelial growth factors. Cardiovasc Res. 2005;65:550-63.

21. Ferrara N, Gerber HP, Le Couter J. The biology of VEGF and its receptors. Nat Med. 2003;9:669-76.

22. Geiger F, Bertram H, Berger I, Lorenz H, Wall O, Eckhardt $\mathrm{C}$, et al.Vascular endothelial growth factor gene-activated matrix (VEGF165-GAM) enhances osteogenesis and angiogenesis in large segmental bone defects. J Bone Miner Res. 2005;20:2028-35.

23. Cui Q, Dighe AS, Irvine JN Jr. Combined angiogenic and osteogenic factor delivery for bone regenerative engineering. Curr Pharm Des. 2013;19:3374-83.

24. Fadhil E, Athraa Y. Histologoical and immunohistochemical evaluation of the effect of local exogenous application of VEGF on bone healing. J Bagh Coll Dentistry. 2014;26:108-15.

25. Uchida K, Uchida S, Nitta K, Yumura W, Marumo F, Nihei H. Glomerular endothelial cells in culture express and secrete vascular endothelial growth factor. Am J Physiol. 1994;266:F81-8.

26. Nissen NN, Polverini PJ, Koch AE, Volin MV, Gamelli RL, Dipietro LA. Vascular endothelial growth factor mediates angiogenic activity during the proliferative phase of wound healing. Am J Pathol. 1998;152:144552.

27. Brogi $\mathrm{E}, \mathrm{Wu} \mathrm{T}$, Namiki $\mathrm{A}$, Isner JM. Indirect angiogenic cytokines upregulate VEGF and BFGF gene expression in vascular smooth muscle cells, whereas 
hypoxia up regulates VEGF expression only. Circulation. 1994;90:649-52.

28. Banks RE, Forbes MA, Kinsey SE, Stanley A, Ingham $\mathrm{E}$, Walters C, et al. Release of the angiogenic cytokine vascular endothelial growth factor (VEGF) from platelets: significance for VEGF measurements and cancer biology. Br J Cancer. 1998;77:956-64.

29. Gaudry M, Bregerie O, Andrieu V, El Benna J, Pocidalo MA, Hakim J. Intracellular pool of vascular endothelial growth factor in human neutrophils. Blood. 1997;90:4153-61.

30. Folkman J, Brem H. Angiogenesis and inflammation. In: Gallin J, Goldstein I, Snyderman R, eds. Inflammation: Basic Principles and Clinical Correlates. 2nd ed. New York: Raven Press; 1992:821-39.

31. Yoshida A, Anand-Apte B, Zetter BR. Differential endothelial migration and proliferation to basic fibroblast growth factor and vascular endothelial growth factor. Growth Factors. 1996;13:57-64.

32. Yebra M, Parry GC, Stromblad S, Mackman N, Rosenberg S, Mueller BM, et al. Requirement of receptor-bound urokinase-type plasminogen activator for integrin alphavbeta5-directed cell migration. J Biol Chem. 1996;271:29393-9.

33. Bao P, Kodra A, Tomic-Canic M, Golinko MS, Ehrlich HP, Brem H. The role of vascular endothelial growth factor in wound healing. J Surg Res. 2009;153:347-58.

34. Brem H, Folkman J. Angiogenesis and basic fibroblast growth factor during wound healing. In: Friedlander GE, Lane JM, eds. Bone Formation and Repair. Rosemont: American Academy of Orthopedic Surgeons; 1994: 213-22.

35. Toi M, Matsumoto T, Bandoh H. Vascular endothelial growth factor: its prognostic implications. Lancet Oncol. 2001;2:667-73.

36. Ferrari G, Scagolitti GV. Serum and urinary vascular endothelial growth factor levels in non - small cell lung cancer patients. Eur J Cancer. 1996;32:2368-9.

37. Kakizawa H, Itoh M, Itoh Y, Imamura S, Ishiwata Y, Matsumoto T, et al. The relationship between glycemic control and plasma vascular endothelial growth factor and endothelin-1 concentration in diabetic patients. Metabolism. 2004;53:550-5.

38. Miller JW, Adamis AP, Shima DT, D Amore PA, Moulton RS, O Reilly MS, et al. Vascular endothelial growth factor \ vascular permeability factor is temporally and spatially correlated with ocular angiogenesis in a primate model. AMJ Pathol. 1994;145:574-84.

39. Takayama M, Shimmer K, Hasegawa H, Tani M, Wakabayashi T, Shinoda K, et al. Clinical role of vascular endothelial growth factor (VEGF) and hepatocyte growth factor (HGF) in type -2 diabetic patients. J Jap Diab Soc. 2000;43:347-54.
40. Kono T, Shigemastu N, Takahashi T, Tabata H, Tanaka A, Ueda M . The relations of vascular endothelial growth factor (VEGF) and microvascular disorder during early wound healing of periodontal defects in model rats with type 2 diabetes mellitus. Jpn J Conserve Dent. 2010;53:601-10.

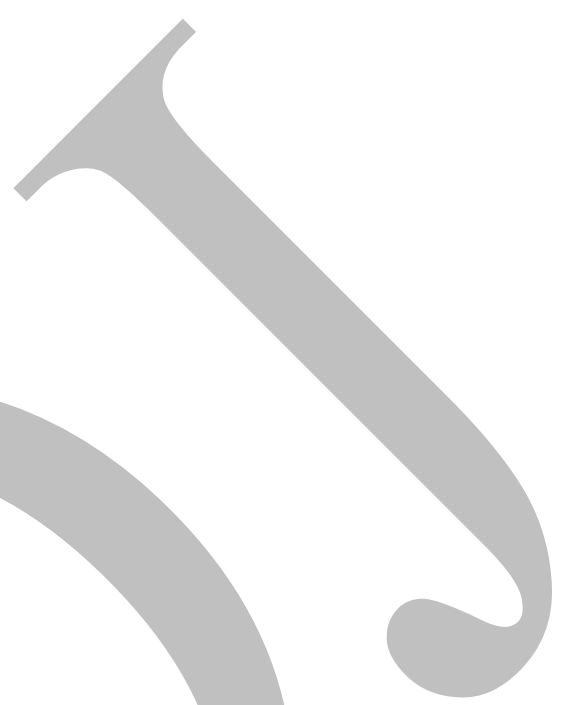

